\section{The Impact of Social Strategies through Smartphones on the Saudi Learners' Socio-cultural Autonomy in EFL Reading Context}

\author{
Ali Abbas Falah ALZUBI ${ }^{1}$, Manjet KAUR A/P Mehar SINGH²
}

Received: $\quad 28$ July 2018
Revised: $\quad 31$ August 2018
Accepted: $\quad$ 04 September 2018
ISSN: $1307-9298$
Copyright @ IEJEE
www.iejee.com

DOI: $10.26822 /$ iejee.2018143958

\begin{abstract}
This study investigated the impact of social strategies mediated by smartphone features and applications on socio-cultural autonomy in English as a Foreign Language (EFL) reading context among undergraduates in Saudi Arabia. Two EFL reading classes of 70 students acted as an experimental and a control group participated in this study. A questionnaire was administered to collect the quantitative data from the participants prior to and post the interventional programme. The experimental group utilised their own smartphone features and applications (dictionaries, WhatsApp, camera, internet search engines, notes, and recorders) to employ the social strategies of asking for clarification and correction, cooperating and empathising with others inside and outside the classroom for 12 weeks whereas the control group learned using the traditional methods. The findings of the study revealed that the employment of social strategies mediated by smartphone features and applications promoted the learners' socio-culturally autonomous learning characteristics of interaction, interdependence, self-regulation, self-worth, mutual support, and understating in EFL reading context. It is recommended strategy use training programmes and smartphones integration in language learning should be highly considered in curricula design, teaching and learning methods, training programmes in order to empower learners to take more responsible roles in the learning of EFL reading skills.
\end{abstract}

Keywords: Reading skill, Saudi Arabia, social strategies, smartphones, socio-cultural autonomy

\section{Introduction}

Successful foreign/second language learning requires interaction with people and communication in the target language. In order for learners to comprehend and improve their reading skills better, they need to interact, cooperate and empathise with others. EFL reading in the Saudi context is problematic. The average results of TOEFL and IELTS tests proved to be the lowest in EFL reading among the Middle East (13 out 20; 4.8 out of 9) (ETS, 2016; IELTS, 2015) respectively. EFL learners in Saudi Arabia at university are less motivated, highly dependent, less interactive and less responsible (Al-Qahtani, 2016; Nezami, 2012; Tamer, 2013). They are unable to learn English language on their own, interact and communicate with others, and study alone. These discouraging habits that contribute negatively to the achievement of English language skills are attributed to many reasons including dominant teacher-centeredness, role learning habits, less exposure to language, inappropriateness of learning materials, lack of skill training programmes (Al-Qahtani; Al-Saadi, 2011; Tamer, 2013). Learners lacking how to interact with others (socio-cultural perspective) would result in low level of achievement and limit their responsibility and control to tackle their own English language learning inside and outside the classroom (Oxford, 2003).

The EFL learners' use of language learning strategies can impact their autonomous learning features and then improve their reading competence and achievement (Alrabai, 2014; Al-Shumaimeri, 2003; Rahman \& Alhaisoni, 2013; Kasper, Uibu, \& Mikk, 2018).This study, part of a large project on the investigation of language learning strategies (LLS) through smartphones that impact the learners' psychological and socio-cultural autonomy in EFL reading skills at university in Saudi Arabia, reports the quantitative data collected through a pre and post questionnaire about the employment of social strategies (SS) through smartphones inside and outside the classroom that impact the learners' features of socio-cultural autonomy (SA) of interaction, self-regulation, self-worth, feedback, and interdependence in EFL reading skills.

\section{Social Strategies}

Benson and Cooker (2013, p.1) argue that "language learning is a social process in the double sense that it is grounded in social interaction and conditioned by social, cultural and historical contexts". Social strategies are social acts that learners employ in order to understand better in the target language (Etxebarria, Garay \& Romero, 2012). Social strategies contribute to increasing the learners' interaction and empathetic understanding as they occur among and between people (Canale, 1983). Learners are required to use appropriate social strategies in order to communicate with other people (Oxford, 1990, p.144). Social strategies are used to aid learners within a particular socio-cultural setting involving cooperation and awareness (Oxford, 2008, p. 52). They are also a means of success and achievement in foreign/second language context (Varisoglu, 2016). Based on Oxford (1990), social strategies compromise three sub-strategies: asking questions for clarification and correction, cooperating with peers and proficient users of the language, and empathizing with others to develop cultural understanding and become aware of their thoughts and feelings. 
Social interaction through asking questions would aid the EFL learners' understanding, provision of large amount of input, and indirect feedback about the learner's production skills. Learners can use this strategy to have more clarification on something not understood or verification to check whether something is correct (Oxford, 1990, p.145). Asking for clarification or verification involves 'Asking the speaker to repeat, paraphrase, explain, slow down, or give examples' (p. 146). For example, the learner can ask the teacher during doing a reading task; can you repeat that? What was that again, I cannot get you. Cooperating with others (temporary pair or small group peers, native speakers, and proficient users) is necessary for language learners. This strategy includes a cooperative task structure or reward structure that push for positive interdependence and mutual support.

Cooperating with others on learning a second/foreign language would improve language performance, self-worth, and social acceptance. Cooperating with peers involves a concerted efforts together with other learners in a reading activity with a common aim (e.g., the learner in groups can do one part of the reading passage, and at the end, the whole group will have to work together to find out the entire story). Working with proficient users of the target language on the job, in the classroom, on a trip, or online to understand better and thus perform well. For instance, the learner can text his\her English friend to help him with a reading passage about the American culture. Oxford (1990) highlights the importance of cooperation with others about language learning and says 'Cooperation is at the heart of many current language instruction practices.'(p.251) Cooperation in language learning can contribute to the development of learners' abilities of listening and activating the understanding skills of others (Varisoglu, 2016), success in language learning (Slavin, 1988); transfer the language into different aspects and spheres Jacobs, 2006).

Empathy is 'the ability to put yourself in someone else's shoes in order to better understand that persons' perspective.' (Oxford, 1990, p. 146) It is very important for both communication and language learning to help increase learners' ability to empathize by developing cultural understanding and becoming aware of others' thoughts and feelings. Cultural understanding is to try to empathize with another person through learning about his/her culture and to try to understand his \her relation to that culture so as to better understand what is read in the target language. Cultural understanding happens through reading about the culture of the second/foreign language, i.e. to get the flavour of the language (Oxford, 1990, pp. 147, 172). Learners need also to observe the behaviours of others as a possible expression of their thoughts and feelings; and when suitable, asking about their thoughts and feelings ( $p$. 147). Such awareness may bring learners closer to the people they face, assist them understand better the communicated message, and suggest what to do accordingly. In reading, learners can sense people's feelings and thoughts through tracing them in notes, texts, letters, articles, memos, and so on (ibid, p. 173).

\section{Socio-cultural Autonomy}

With the calls for the language learners' empowerment to take more responsible roles in learning, learner autonomy (LA) has emerged. It refers to the learners' ability to take charge of their own language learning (Holec, 1981). Holec (1981) operationalises LA in the learners' responsibility towards their second/foreign language learning in the determination of language learning objectives, definition of the contents and the progressions, selection of methods and techniques, monitoring the procedure of acquisition (rhythm, time, place, etc.), and evaluation of what has been acquired. Holec has inspired all later researchers to present various perceptions, definitions, and models of LA in EFL contexts (Benson, 1997; Cotterall, 1995; Dickinson, 1987; Holec, 1981; Little, 1991; Oxford, 2003; Pennycook, 1997). Oxford (2003) proposed a more comprehensive systematic model for LA including four perspectives: technical perspective, psychological perspective, socio-cultural perspective, and political-critical perspective. Oxford's model emphasises four main themes in each perspective: context, agency, motivation, and learning strategies (Oxford, 2003, pp. 80-81).

Oxford (2003) argues that the socio-cultural autonomy (SA) concentrates on the socially mediated learning. This perspective makes use of the social interaction, as an essential part of the overall of the learners' cognitive development. It mainly focuses on the development of human capacity via interaction. In this regard, Murase (2007) divides the definition of socio-cultural perspective into social and cultural. The social aspect is about the role of social interaction in developing SA which may include interdependence where learners cooperate with teachers, peers, and people. The cultural aspect inspects the cultural features where SA occurs. The context of learning in SA refers to the presence of society and culture among a group of individuals at a given historical time.

A sort of interaction happens between the learner and more capable people that in turn can help develop his/her language learning. The learners' interaction with others or alone is considered as the zone of proximal development (ZPD) that represents the variation degrees between the learners' performance with or without assistance when learning (Vygotsky, 1978). In other words, learners need the help of the experts to self-direct or automate their language learning. Motivating learners to self-regulate their learning can be enlarged and maximised by the capable others through the process of learning and the mediated learning relationship. Social learning strategies help learners interact with others. They are applied by learners of a second/foreign language via social interaction with more competent people. SA emphasises on the role of community to support learners in a particular place and time. The autonomy of the process on learning in this type is presented in the context rather in the learner exercising it (Norton, 2000, 2001).

The context of autonomy hypothesises that the community in which the relationship and social and cultural environment can help learners receive insider knowledge, cultural understanding, practice, and strategies through interaction (Oxford, 2003). Language learning strategies such as social strategies can help learners communicate with the people of the language they are learning (Oxford, 1990). Little (2009, pp.224-226) pointed out that learners should participate in the selection of learning aims, methods, content of learning, and assignments to carry out through the channels of negotiation and agreement with others.

In summary, Oxford (2003) views SA as a self-regulation, gained through interaction with more capable, mediating person in a particular setting. Mediating can also happen through other means such as book or technology. Context in SA is seen as the relationship between learners and more capable other, as well as social and cultural settings. It can be also communities of practice. Agency in SA is the power to control one's own learning through self-regulation and active participation with other practitioners. Motivation in SA is linked to becoming self-regulated individual and part of the community of practice. Learning strategies in SA refer to the strategies that learners employ and learn when interacting with the community of practice. In this study, 
context will be foreign language environment where the foreign language is not practised by the majority (Green \& Oxford, 1995). Agency will be represented in the learners use of social strategies through their own smartphone features and applications in the learning of EFL reading skills. Motivation will be the learners' ability to regulate their own learning of reading skills. Learning strategies will be social strategies (SS) by Oxford (1990) that concern the development of SA. Social strategies are believed to facilitate the language learners' communication within the socio-cultural context (Oxford, 2011). EFL Saudi undergraduates are considered less interactive, less interdependent, less self-regulated, less mutually supported, and less self-worthy in foreign language learning maybe due to a number of reasons including the lack of interaction with capable people, lack of language exposure, lack of using technology in language learning (Alharbi, 2017).

\section{Smartphones}

Mobile-assisted language learning (MALL) refers to the enhancement of language learning through the use of handheld and mobile devices, such as personal digital assistants, players, tablets, and smartphones (Kukulska-Hulme \& Shield, 2008; Persson \& Nouri, 2018). The use of smartphones has been as essential tools that facilitate the employment of language learning strategies (LLS) and thus improve learner autonomy (LA) in EFL context. Smartphones provide a blueprint for autonomous learning (Reinders, 2010). Recent research has highlighted the role of mobiles in foreign/second language learning (Almekhlafy \& Alzubi, 2016; Ahmed, 2015; Chen, \& Hsieh, 2008; Chinnery, 2006; Godwin-Jones, 2011; Hazaea \& Alzubi, 2016; Kukulska-Hulme \& Traxler, 2005; Rahimi, \& Miri, 2014; Palfreyman, 2012; Seddigh \& Shokrpur, 2012; Thornton \& Houser 2003; Wong, Chin, Tan, \& Liu, 2010). Mobiles are inevitably a means of independent language learning (Clarke \& Svanaes, 2015; Nino, 2015; Persson \& Nouri, 2018). Nino (2015) who surveyed language learners' perceptions and experiences on the use of mobile devices to support their independent language learning in higher education claimed that mobiles are suitable for passive language skills such as the acquisition of vocabulary, written and oral comprehension, pronunciation, and grammar.

Interaction with others, as a very important means of language learning, can be enhanced through social strategies (SS) (Oxford, 2006). Previous research has highlighted the role of social strategies to facilitate interaction (Clouston, 1997); make language learning more effective (Habte, 2000); and improve the learners' autonomy (Antonio, 2017). SS are very important because they allow language learners to communicate with others either in real and/or virtual (online) life. For example, learners will be able to ask questions, collaborate inside and/or outside the classroom through a social network, and notice cultural aspects when reading a passage. Etxebarria, Garay, and Romero $(2012$, p.279) argue that the use of technology and internet (e.g., Moodle e-learning platform), deigned to support the promotion of feedback or interaction, can assist in the development of social learning strategies and facilitate their use into a more realistic and plausible method. Moodle includes channels designed for Moodle includes 'actions that the apprentice carries out with the help of others and that help him to understand, learn and gather information (asking, empathizing, cooperating and practising).' (Etxebarria, Garay, \& Romero,2012, p.279). Mistar (2015) indicated that social learning strategies were used at a high frequency, having acquired relatively learner autonomy (LA) since social strategies require more independent roles in interacting with others. Alharbi (2017) reported that the EFL Saudi learners' use of social strategies in the Australia context was very limited outside the classroom due to cultural aspects, and lack of language confidence. Alharbi's (2017) investigation of social strategies can be maximised in the Saudi context through smartphone technology in order to improve the learners' socio-culturally autonomous characteristics in EFL reading context.

This study is motivated by the assumption that learners who are able to employ language learning strategies in foreign/second learning have better chances to improve their autonomous language learning that enables them to learn on their own (Mistar, 2015; Little, 1997). In addition, Preparatory Year Programmes in Saudi Arabia were established to develop the undergraduates' skills of learning responsibility, critical thinking, active learning, communication, interaction, and independence.

Therefore, in the current study, the use of social strategies (SS) mediated by smartphone features and applications that contribute to the perspective of socio-cultural autonomy (SA) was examined. The social strategies (SS) included the employment of asking for clarification and correction, cooperating, and empathising with others mediated by the smartphone features and applications (dictionaries, WhatsApp, internet search engines, camera, notes, and recorders) both inside and outside the classroom. EFL learners in the Saudi EFL context have a high tendency to take charge of their own language learning; however, the level of learner autonomy (LA) is not encouraging because of the lack of learners' training programmes (Al Asmari, 2013; Alzubi, Manjet, \& Pandian, 2017; Farooq, 2013; Tamer, 2013). Therefore, this study hypotheses that in order for learners to be more interactive, more self-regulated, more interdependent, more self-worthy, more mutually supported, and acquire more understanding of reading skills, they need to employ SS through smartphones in EFL reading context inside and outside the classroom. Therefore, in the light of literature, the current study will address the following research question:

1. To what extent does the use of social strategies through smartphones impact the Saudi learners' socio-cultural autonomy in EFL reading context?

\section{Method}

In this study, a sequential quantitative research design was used to collect the data through a questionnaire prior to and post the interventional programme. The questionnaire collected data on the use of SS mediated by smartphones that impact the learners' socio-cultural autonomy (SA) pre and post the interventional programme in EFL reading context.

\section{Population and Sample of the Study}

The population of the study involved undergraduates enrolled in the Deanship of Preparatory Year at Najran University in Saudi Arabia. Preparatory Year is a programme for two semesters in which students study skills such as English, mathematics, computer, and communication, before they specialise in the faculties of medicine, engineering, computer, and administrative sciences. Preparatory Year has been established to bridge the educational gaps between school and university systems with respect to teaching methods, learning habits of memorisation, teacher and students' roles. In Preparatory Year, students learn how be more responsible and take the initiative in the process of learning so that they can do assignments and tasks on their own. The sample consisted of two intact reading classes totalling 70 students: 35 in the experimental group and 35 in the control group. Purposive sampling was applied to choose the samples of the study. Preparatory Year undergraduates share a number of common features as 
Table 1. Characteristics of the Study Sample

\begin{tabular}{ccc}
\hline Qualities & Experimental Group & Control Group \\
\hline Educational background & High school (science stream) & High school (science stream) \\
\hline English language & Foreign language & Foreign language \\
\hline Age & $18-20$ & $18-20$ \\
\hline Gender & Male & Male \\
\hline Nationality & Saudi Arabia & Saudi Arabia \\
\hline Mother tongue & Arabic & Arabic \\
\hline Use of smartphones & Yes & No \\
\hline Level of study & First year: first semester & First year: first semester
\end{tabular}

shown in the following table (Table 1):

Before implementing the treatment, the teacher-researcher flipped a coin to decide which of the two groups would act the experimental group and which would be the control group (Ary, Jacobs, Sorensen, \& Razavieh, 2010). However, some shift between both groups occurred as some students did not wish to participate in the experimental group due to various reasons like smartphone property and internet access, readiness to utilise smartphones for learning purposes, and voluntary wish to participate in the control and experimental group in the study; therefore they were assigned to the control group and vice versa (White \& Sabarwal, 2014).

\section{Training Programme}

A training programme was held for the students in the experimental group in order to maximise the hoped benefits and assist students in the employment of SS mediated by smartphone features and applications. A qualified teacher conducted the training programme for the experimental group. He has been teaching English as a foreign language for ten years at Najran University and received certificates in training students on the use of language learning strategies (LLS) in various skills from certified institutes. Participants in the experimental group were trained in the first two weeks on how to employ SS through smartphones in relation to the textbook. The training programme was conducted in the first three weeks over 8 sessions. In these sessions, the participants received training on social strategies (SS) of asking for clarification and correction, cooperating with others, and empathising the culture of English speakers. In details, strategy use training was based on Oxford's (1990) model that includes seven implementing steps of strategy use training: determining the learners' needs and resources available for training; assigning the targeted strategies; considering the benefits of strategy use training and the motivational issues; preparing training materials and activities; conducting strategy use training; and evaluating and revising strategy use training. Training included activities based on the content to be covered in the syllabus breakdown of Basic Reading Power 1 (Jeffries \& Mikulecky, 2014) in the 2017- 2018 fall academic year and

Table 2. Distribution of Items in SS and SA Questionnaire the parallel strategies that will be identified to be taught. These activities were provided by the teacher in order to train students on the use of SS, which would enable them to impact their SA in EFL reading context. The activities in the strategy training process also included materials and exercises based on the sample reading activities provided by Oxford (1990) to teach SS in EFL reading context.

\section{Data Collection Procedures and Instruments}

Data were collected through a pre and post questionnaire. The questionnaire prior to the intervention was administered in the first week to the experimental and control group, and then the strategy use interventional programme was implemented to the experimental group for 12 weeks. Then, the post questionnaire was administered to the experimental and control group.

A pre and post questionnaire was used to collect data from the experimental and control group about the use of SS and SA in EFL reading context (research question one). The questionnaire was distributed as hard copy to the control and experimental group inside the classroom with the help of concerned teachers. The questionnaire consists of two parts. The first part includes an adapted version of SS, specific to EFL reading skills from Oxford's (1990) Strategy Inventory of Language Learning (SILL). The purpose of the SILL is to reflect the actual use of the EFL learners' language strategies (Oxford, 1999). SS part includes social strategies (SS) (six items). The second part of the questionnaire includes the features of socio-cultural autonomy (SA). The items of this part were developed by the researcher Grounded on Oxford $(1990,2003)$ and Holec (1981). 7 items are included in this part. The questionnaire indicates how often learners employ SS mediated by smartphones in EFL reading that impact their SA on a five-Likert scale: (' 1 ' never, ' 2 ' rarely, ' 3 ' sometimes, ' 4 ' often, ' 5 ' always). A total of 13 items distributed to six sections as shown in Table 2.

Reliability and validity of the SS and SA questionnaire was checked through Factor Analysis and Cronbach's alpha. The Factor analysis was carried out using Pearson Correlation method to validate the items' grouping in relation

\begin{tabular}{ll}
\hline Domains & Item \\
\hline Social strategies & 1.2 .3 .4 .5 .6 \\
\hline Socio-cultural autonomy & 7.8 .9 .10 .11 .12 .13 \\
\hline
\end{tabular}

to the items of SA. The items have been classified according to their loading to SA based on the level of significance $\left(0.01^{* *}, 0.05^{*}\right)$. As a result, 7 items were most overloaded on SA at $\left(.485^{*}, .486^{*}, .521 *, .645^{* *}, .847^{* *}, .541^{*}, .666^{* *}\right)$. Two items were excluded as they had low loadings (.414,
.422). Following the factor analysis, the questionnaire was administered to a sample of reading class $(n=32)$ other than those who participated in this study. The Cronbach's alpha of the scale registered a total of .84. The internal reliability should be above .7 and not below .6 (Dornyei, 2007, 
p. 207). The internal reliability of domains is as follows: SS (.80), SA (.77).

\section{Data Analysis}

The Statistical Package of the Social Sciences (SPSS) was used to analyse the quantitative data collected by the pre and post SS and SA questionnaire. Five types of SPSS analysis were used to analyse the data of the questionnaires in relation the research question no.1: Descriptive Analysis, Independent t-test, Paired t-test, Correlation Bivariate, and Effect Size.

\section{Results}

It must be noted that 70 students were registered in the experimental and control group, i.e., 35 students in each group. Therefore, the 70 students were assumed to participate in the study as an experimental and a control group. However, only 64 participants appeared in the two classes (32 in each class) and completed the pre SS and SA questionnaire before the interventional programme. However, 59 participants: 30 participants in the experimental group and 29 participants in the control group completed the post SS and SA questionnaires. This decrease is attributed

Table 3. Analysis of Participants' Responses to Pre SS and SA Questionnaire

\begin{tabular}{|c|c|c|c|c|c|}
\hline \multicolumn{2}{|c|}{ Social Strategies } & \multirow{2}{*}{$\begin{array}{l}\text { Group } \\
\text { Experimental }\end{array}$} & \multirow{2}{*}{$\frac{N}{32}$} & \multirow{2}{*}{$\begin{array}{r}M \\
2.25\end{array}$} & \multirow{2}{*}{$\frac{S D}{1.320}$} \\
\hline 1 & $\begin{array}{l}\text { Ask the other person to slow down or say } \\
\text { it again if I do not understand something in } \\
\text { reading. }\end{array}$ & & & & \\
\hline & & Control & 32 & 2.34 & 1.153 \\
\hline \multirow[t]{2}{*}{2} & $\begin{array}{l}\text { Ask people whose English is better than mine } \\
\text { to correct me when I read. }\end{array}$ & Experimental & 32 & 2.81 & 1.061 \\
\hline & & Control & 32 & 2.53 & 1.344 \\
\hline \multirow[t]{2}{*}{3} & Practise English with other students. & Experimental & 32 & 2.34 & 1.181 \\
\hline & & Control & 32 & 2.50 & 1.164 \\
\hline \multirow[t]{2}{*}{4} & $\begin{array}{l}\text { Ask for help from good speakers of English } \\
\text { when doing a reading task. }\end{array}$ & Experimental & 32 & 3.03 & 1.204 \\
\hline & & Control & 32 & 2.56 & 1.190 \\
\hline \multirow[t]{2}{*}{5} & Ask questions about a reading passage. & Experimental & 32 & 2.38 & 1.238 \\
\hline & & Control & 32 & 2.34 & 1.066 \\
\hline \multirow[t]{4}{*}{6} & $\begin{array}{l}\text { Try to read about the culture of English } \\
\text { speakers. }\end{array}$ & Experimental & 32 & 2.66 & 1.234 \\
\hline & & Control & 32 & 2.22 & 1.184 \\
\hline & Overall & Experimental & 32 & 2.58 & .649 \\
\hline & & Control & 32 & 2.42 & .764 \\
\hline \multicolumn{6}{|c|}{ Socio-cultural Autonomy } \\
\hline \multirow[t]{2}{*}{7} & $\begin{array}{l}\text { I am satisfied when I cooperate with others } \\
\text { in learning reading. }\end{array}$ & Experimental & 32 & 3.75 & 1.218 \\
\hline & & Control & 32 & 3.56 & 1.190 \\
\hline \multirow[t]{2}{*}{8} & $\begin{array}{l}\text { I have a stronger motivation towards learn- } \\
\text { ing reading. }\end{array}$ & Experimental & 32 & 3.38 & 1.314 \\
\hline & & Control & 32 & 3.22 & 1.313 \\
\hline \multirow[t]{2}{*}{9} & I have more reading practice opportunities. & Experimental & 32 & 2.94 & .982 \\
\hline & & Control & 32 & 2.72 & 1.276 \\
\hline \multirow[t]{2}{*}{10} & $\begin{array}{l}\text { I get more feedback about my reading } \\
\text { errors. }\end{array}$ & Experimental & 32 & 2.31 & 1.120 \\
\hline & & Control & 32 & 2.47 & 1.270 \\
\hline \multirow[t]{2}{*}{11} & $\begin{array}{l}\text { I get greater use of different reading func- } \\
\text { tions. }\end{array}$ & Experimental & 32 & 2.56 & 1.076 \\
\hline & & Control & 32 & 2.41 & 1.160 \\
\hline \multirow[t]{2}{*}{12} & $\begin{array}{l}\text { I empathise with others through their cul- } \\
\text { ture, feelings, and attitudes. }\end{array}$ & Experimental & 32 & 3.16 & 1.347 \\
\hline & & Control & 32 & 2.88 & 1.264 \\
\hline \multirow[t]{3}{*}{13} & $\begin{array}{l}\text { I analyse the social identities in reading } \\
\text { passages. }\end{array}$ & Experimental & 32 & 2.25 & 1.164 \\
\hline & Overall & Control & 32 & 2.91 & .693 \\
\hline & & Experimental & 32 & 2.83 & .577 \\
\hline
\end{tabular}


to withdrawal, absence deprival, and/or course dropping.

Research Question 1- To what extent does the use of social strategies through smartphones impact the Saudi learners'socio-cultural autonomy in EFL reading context?

According to Table 3, social strategies (SS) scored a means of 2.58 and 2.42 , and stranded deviations of .649 and .764 in respect of the experimental and control group. This means that participants in the experimental group (52\%) and in the control group (48\%) sometimes use the smartphone features and applications to employ the social strategies (SS). Both groups show very close results in all items $(1,2,3,5,6)$ of the subscale except for item 4 in which the experimental group (62\%) 'often' asked for help from good speakers of English when doing a reading task through smartphones $(M=3.03 ; S D=1.204)$, the control group had a means of $2.56(51 \%)$ and standard deviation of 1.238 . According to the means and standard deviations shown in Table 3, the experimental group (58\%) and control group

Table 4. Analysis of Pre SS and SA Questionnaire

\begin{tabular}{cccccccccc}
\hline Domains & Group & $N$ & $M$ & $S D$ & $t$ & df & $\begin{array}{c}\text { Sig. } \\
\text { (2-tailed) }\end{array}$ & $\begin{array}{c}\text { Mean } \\
\text { Difference }\end{array}$ & $\begin{array}{c}\text { St. Error } \\
\text { Difference }\end{array}$ \\
\hline Social strategies & Experimental & 32 & 2.58 & .649 & .911 & 62 & .366 & .161 & .177 \\
\hline Cocio-cultural Autonomy & Experimental & 32 & 2.91 & .693 & .448 & 62 & .656 & .071 & .159 \\
\hline & Control & 32 & 2.83 & .577 & & & & & \\
\hline
\end{tabular}

egies (SS). Both groups show very close results in all items $(1,2,3,5,6)$ of the subscale except for item 4 in which the experimental group (62\%) 'often' asked for help from good speakers of English when doing a reading task through smartphones $(M=3.03 ; S D=1.204)$, the control group had a means of $2.56(51 \%)$ and standard deviation of 1.238 . According to the means and standard deviations shown in Table 3, the experimental group (58\%) and control group (57\%) 'sometimes' employ the features of socio-cultural autonomy (SA) in EFL reading course. Participants in both groups are often satisfied when they cooperate with others in learning reading $(M=3.75,3.56, S D=1.21,1.19)$ and have a stronger motivation towards learning reading $(M=3.38$, $3.22, S D=1.31,1.31$ ). They sometimes get more feedback about reading errors and analyse the social identities in reading passages $(M=2.31,2.47, S D=1.12,1.07)$.

Table 4 displays the statistical significances of SS and SA between the experimental (Exp.) and control (Cont.) group prior to the interventional programme.

As per Table 4, there is not a significant difference in the scores of social strategies (SS) between the experimental group $(M=$ $2.58, S D=0.649)$ and the control group $(M=2.42, S D=0.764)$ : $t(62)=0.911, p=0.366$ prior to the interventional programme. The table also showed that no statistically significant differences do exist in the scores of socio-cultural autonomy (SA) between the experimental group $(M=2.91, S D=0.693)$ and control group $(M=2.83, S D=0.577) ; t(62)=0.448, p=.656$ respectively. These statistics indicate the equality which both groups: experimental and control share before the interventional programme. This result proves that both groups: experimental and control do experience equivalent use of SS and SA prior to the interventional programme and ensures that both groups are similar, thus adding to the groups' homogeneity.

\section{Post SS and SA Questionnaire}

The findings of data analysis of post SS and SA questionnaire showed that there is a variance in the use of SS between the experimental and control group. In details, participants in the experimental group who utilised smartphone features and applications to assist them in the employment of SS outperformed the control group. The 'often' use marked the experimental group's employment of SS in the learning of EFL reading skills. The findings of the questionnaire also indicated a variance in the use of SA between the experimental group and control group. To further explain, participants in the experimental post the intervention 'always' employed SA in the learning of EFL reading skills compared with 'often' in the control group. Table 5 shows the independent t-test, significance, and effect size of the interventional programme.

Table 5 shows that $80 \%$ of the participants in the experimental group employed the social strategies through smartphones $(M=4.02, S D=.746)$ compared with $60 \%$ in the control group $(M=$ $3.01, S D=.500$ ). In details, the data revealed that participants in the experimental group 'always' asked people to correct them $(M=4.40, S D=.968)$ and always asked for help from good English speakers when doing reading $(M=4.33, S D=1.02)$ compared with 'often' $(M=3.31,3.10, S D=.850, .976)$ in the control group respectively. Trying to read about the culture of English speakers scored the least between the two groups $(M=3.17$, $2.72, S D=1.11,1.38$ ) in favour of the experimental group. Table 5 also shows that $87 \%$ of participants in the experimental group $(M=4.34, S D=.493)$ showed improvement in their autonomous features of socio-culture better compared with $64 \%$ in the control group $(M=3.20, S D=.381)$. Participants in the experimental group are 'always' satisfied when they cooperate with other people and strongly motivated to learn reading $(M=4.63,4.73$, $S D=.669, .521)$ compared with 'often' in the control group $(M=$ $3.59,3.28, S D=1.81, .996)$. Noticeable variance has been scored in the results of the two groups in getting greater use of different reading functions $(M=4.20,2.72, S D=.961,1.06)$ and analysing the social identities in reading passages $(M=4.00,2.90, S D=108$, 1.08 ) in favour of the experimental group.

In Table 6, it is clear that the use of SS mediated through smartphones by the experimental group in EFL reading course is significant $(M=4.02, S D=.746)$ compared with the control group who learned using the traditional methods $(M=3.01, S D=.500)$; $t(57)=6.060, p=.000$ ). Participants in the experimental group outperformed the control group in the use of SS in the learning of EFL reading skills. Table 6 also displays that the significant use of SA among the participants in the experimental group $(M=4.34, S D=.493)$ and control group $(M=3.20, S D=.381)$ post the interventional programme proved to be significant in favour of the participants in the experimental group $t(57)=9.969, p=.000$ ). Comparing the findings with the pre data analysis of both the control and experimental group, it is noticed that the experimental group improved their SA better in EFL reading context attributed to the SS interventional programme.

In order to measure how much effective the SS programme was, the effect size of the programme was measured using Eta squared post the interventional programme. It must be noted that the effect size was calculated after comparing the results of the experimental group with those of the control group based on the analysis of post SS and SA questionnaire after the interventional programme in order to take into consideration 
Table 5. Analysis of Participants' Responses to Post SS and SA Questionnaire

\begin{tabular}{|c|c|c|c|c|}
\hline Social Strategies & Group & N & M & $S D$ \\
\hline \multirow{2}{*}{$\begin{array}{l}1 \text { Ask the other person to slow down or say it again if I do not understand some- } \\
\text { thing in reading. }\end{array}$} & Experimental & 30 & 4.17 & 1.234 \\
\hline & Control & 29 & 3.03 & .823 \\
\hline \multirow[t]{2}{*}{2 Ask people whose English is better than mine to correct me when I read. } & Experimental & 30 & 4.40 & .968 \\
\hline & Control & 29 & 3.31 & .850 \\
\hline \multirow[t]{2}{*}{3 Practise English with other students. } & Experimental & 30 & 4.30 & 1.179 \\
\hline & Control & 29 & 3.00 & 1.102 \\
\hline \multirow[t]{2}{*}{4 Ask for help from good speakers of English when doing a reading task. } & Experimental & 30 & 4.33 & 1.028 \\
\hline & Control & 29 & 3.10 & .976 \\
\hline \multirow[t]{2}{*}{5 Ask questions about a reading passage. } & Experimental & 30 & 3.73 & 1.363 \\
\hline & Control & 29 & 2.90 & .724 \\
\hline \multirow[t]{2}{*}{6 Try to read about the culture of English speakers. } & Experimental & 30 & 3.17 & 1.117 \\
\hline & Control & 29 & 2.72 & 1.386 \\
\hline \multirow[t]{2}{*}{ Overall } & Experimental & 30 & 4.02 & .746 \\
\hline & Control & 29 & 3.01 & .500 \\
\hline \multirow[t]{2}{*}{7 I am satisfied when I cooperate with others in learning reading. } & Experimental & 30 & 4.63 & .669 \\
\hline & Control & 29 & 3.59 & 1.181 \\
\hline \multirow[t]{2}{*}{8 I have a stronger motivation towards learning reading. } & Experimental & 30 & 4.73 & .521 \\
\hline & Control & 29 & 3.28 & .996 \\
\hline \multirow[t]{2}{*}{9 I have more reading practice opportunities. } & Experimental & 30 & 4.43 & .898 \\
\hline & Control & 29 & 3.17 & .805 \\
\hline \multirow[t]{2}{*}{10 I get more feedback about my reading errors. } & Experimental & 30 & 4.07 & 1.172 \\
\hline & Control & 29 & 3.17 & 1.002 \\
\hline \multirow[t]{2}{*}{11 I get greater use of different reading functions. } & Experimental & 30 & 4.20 & .961 \\
\hline & Control & 29 & 2.72 & 1.066 \\
\hline \multirow[t]{2}{*}{12 I empathise with others through their culture, feelings, and attitudes. } & Experimental & 30 & 4.33 & .884 \\
\hline & Control & 29 & 3.55 & 1.088 \\
\hline \multirow[t]{2}{*}{13 I analyse the social identities in reading passages. } & Experimental & 30 & 4.00 & 1.083 \\
\hline & Experimental & 30 & 4.34 & .493 \\
\hline Overall & Control & 29 & 3.20 & .381 \\
\hline
\end{tabular}

the learners' educational development that may happen in regular classes by the end of the course. Cohen (1988) suggested a criterion to interpret the results extracted by Eta Squared $(.01=$ small; $.06=$ moderate; $.14=$ large). Table 6 shows that the SS programme has moderately impacted the participants' performance in the experimental group (Eta=.392). The Correlation Bivariate (Pearson Correlation) analysis was applied to correlate the relationship between the use of SS and SA post the interventional programme. The results of analysis showed that the correlation between SS and SA is at the level of 0.01 which means that there is a significant relationship between SS and SA scales at the overall $\left(.662^{* *}\right)$. Finally, SS and SA are strongly related; the more SS are employed, the more SA is promoted among EFL learners in reading.

\section{Discussion}

To what extent does the use of social strategies through smartphones impact the Saudi learners' socio-cultural autonomy in EFL reading context?

Social strategies (SS) are very important in the promotion of socio-cultural autonomy (SA) in EFL reading context. This role is enlarged through the utilisation of smartphone features and applications. The learners' employment of SS mediated by smartphones has promoted their socio-culturally autonomous features. Learners have become more interactive with peers, and teachers who helped them acquire more independent language learning roles. Learners were also motivated through self-reg-

Table 6. Analysis of Post SS and SA Questionnaire

\begin{tabular}{|c|c|c|c|c|c|c|c|c|c|}
\hline Domains & Group & $N$ & $M$ & $s d$ & $t$ & $d f$ & $\begin{array}{c}\text { Sig. } \\
\text { (2-tailed) }\end{array}$ & $\begin{array}{l}\text { Mean Dif- } \\
\text { ference } \\
\text { (MD) }\end{array}$ & $n^{2}$ \\
\hline \multirow[t]{2}{*}{ Social Strategies } & Experimental & 30 & 4.02 & .746 & \multirow[t]{2}{*}{6.060} & 57 & \multirow[t]{2}{*}{.000} & \multirow[t]{2}{*}{1.005} & .392 \\
\hline & Control & 29 & 3.01 & .500 & & 57 & & & \\
\hline \multirow[t]{2}{*}{ Socio-cultural Autonomy } & Experimental & 30 & 4.34 & .493 & \multirow[t]{2}{*}{9.969} & 57 & \multirow[t]{2}{*}{.000} & \multirow[t]{2}{*}{1.146} & \\
\hline & Control & 29 & 3.20 & .381 & & 57 & & & \\
\hline
\end{tabular}


ulating their own learning and were confident. In addition, the self-employment of SS has improved their understanding and contributed to their achievement and performance in EFL reading skills. The findings of the interventional programme on SS revealed a moderate effectiveness of the SS interventional programme to enhance the EFL readers' socio-cultural autonomy (SA) in EFL reading context, where strong relationship found between SS and SA. The data analysis of post LLS questionnaires showed that $80 \%$ of participants in the experimental group who utilised smartphone features and applications to employ social strategies (SS) of asking, cooperating, and empathising with others, significantly outperformed those who acted as the control group (60\%). The findings of the data analysis of the questionnaire prior to and post the SS interventional programme revealed that $87 \%$ of participants in experimental group did better in the acquisition of socio-culturally autonomous characteristics than the control group (64\%).

The findings of the current study are further confirmation of what previous research and literature reported on the relationship between language learning strategies (LLS) and learner autonomy (LA) in EFL context (Ceylan, 2015, 2017; Chen \&Pan, 2015; Hismanoglu, 2000; Holec, 1981; Mistar, 2015; Nguyen \& Gu, 2013; O'Malley \& Chamot, 1990; Oxford, 1991, 2003; Reinders \& Hubbard, 2013; Salehi, Ebrahimi, Sattar, \& Shojaee, 2015; Su \& Duo, 2010; Timirbaeva, 2013). The findings of high use of social strategies through smartphones are in line with Mistar (2015) who reported that learners acquired some degrees of autonomy where social strategies require them to independently enhance communicative interactions with other people. The findings are also in line with Antonio (2017) who reported that the use of social strategies in EFL context improved the autonomous features of learners in terms of taking an active role over the communicative situations. Learners managed to use the expressions for clarification, cooperate with their classmates in order to solve a linguistic task and to use conversational strategies, and convey ideas and points of view naturally. These findings are in agreement with Nino (2015) who reported that language learners employed their mobile applications of videos, newspapers, language practice to comprehend language skills such as reading, listening, and speaking; dictionaries and translation applications to get the meaning of new words; flashcard and not taking applications to memorise new words; chat or messenger applications to communicate with other people; and games applications to learn with fun to enhance their independent language learning at university. Unlikely, the results of the level of SS reported in this study are not in line with Etxebarria, Garay and Romero (2012) who reported the low use of social strategies through the Moodle e-learning platform for linguistic purposes because of the lack of habit of using the Internet and tools of e-learning platforms to learn the target language. The researchers proposed that the creation of a methodological standard where teachers and students have clear ideas about which Moodle tools could foster and facilitate the development of each social strategy.

\section{Conclusion}

The current study has uncovered the effectiveness of social strategies (SS) mediated by smartphone features and applications that impact the learners' socio-cultural autonomy (SA) in EFL reading context. Learners have highly employed the social strategies of asking for clarification, and correction, cooperating, and empathising with others through smartphones. Therefore, they have become more interdependent, interactive with others, self-regulated, active, self-worthy, and part of the community of service. They have also improved their understanding of the EFL reading skills, mutual support, and social acceptance, received large amount of input, and indirect feedback about the learners' production skills. In other words, learners have become more satisfied when cooperating with others, got more chances to read and feedback about reading, emphasised with others through culture, feelings, and attitudes, and analysed the social identified in reading texts.

\section{Recommendations and Future Research}

The effectiveness of the SS training programme has empowered learners of reading skills with more autonomous features of interaction with others, interdependence, self-worth, social acceptance, self-regulation, active participation, and feedback. These autonomous features would finally contribute to more understanding of reading texts, larger amount of input, and provision of indirect feedback about the learners' production skills proved by the findings of the current study could serve as starting point to for training sessions and programmes for learners in EFL reading context to assist their autonomous learning characteristics. The findings of the current study could also serve as strong base to take further actions to vary the EFL learning methods through allowing the use of smartphone features and applications as important parties in the learning process of EFL reading skills inside and outside the classroom.

The current study investigated the employment of social strategies (SS) through smartphones that impacted the learners' socio-cultural autonomy (SA) in EFL reading context. Researchers are urged to examine the use social strategies through smartphones that impact the socio-cultural autonomy (SA) in the learning of other language skills such as listening, speaking, and/ or writing. Future research is also encouraged to examine the use of SS through smartphones that impact the socio-cultural autonomy ( $\mathrm{SA}$ ) in EFL reading context among female undergraduates.

The study has two limitations. First, the findings of the study is only generalised on Preparatory Year male undergraduates of Najran University. Second, male students were only included in the current study due to cultural restrictions regarding gender-based educational segregation where female students are only taught by female teachers, male students are only taught by male teachers. Further to that, female students are not allowed with smartphones inside faculties and classrooms, so it was impossible to implement the programme in the female section.

\section{References}

Ahmed, M. D. (2015). Can Smartphones Pave the Path towards EFL Competence for Saudi College Students? Education and Linguistics Research, 1(2), 120-144.

Al Asmari, A. (2013). Practices and Prospects of Learner Autonomy: Teachers' Perceptions. English Language Teaching 6(3), 1-10.

Alharbi, A. (2017). The Social language strategies of Saudi students in an English as a second language context (doctoral dissertation). Rmit University, Australia.

Almekhlafy, A. \& Alzubi, A. A. F. (2016). Mobile-Mediated Communication a Tool for Language Exposure in EFL Informal Learning Settings. Arab World English Journal, 7(1), 388-407.

Al-Qahtani, A. (2016). Why Do Saudi EFL Readers Exhibit Poor Reading Abilities? English Language and Literature Studies, 6(1), 1-15.

Alrabai, F. (2014). Motivational Practices in English as a Foreign Language Classes in Saudi Arabia: Teachers Beliefs and Learners Perceptions. Arab World English Journal, 5(1), 21-37.

Al-Saadi, H. M. (2011). From Spoon Feeding to Self-Feeding: 
Helping Learners Take Control of Their Own Learning. Arab World English Journal, 2(3), 95-114.

Al-Shumaimeri, Y. A. (2003). A study of Classroom Exposure to oral pedagogic tasks in relation to the motivation and performance of Saudi secondary school learners of English in a context of potential curriculum reform (doctoral dissertation). University of Leeds, UK.

Alzubi, A. A. F., Manjet, K., \& Pandian, A. (2017). The Use of Learner Autonomy in English as a Foreign Language Context among Saudi Undergraduates Enrolled in Preparatory Year Deanship at Najran University. Advances in Language and Literary Studies, 8(2), 152-160.

Antonio, A. (2017). Language interaction through the instruction of social learning strategies in an EFL group of tenth graders at the IE La Despensa, Soacha, Colombia (Bachelor thesis). Universidad Santo Tomás, Colombia.

Ary, D., Jacobs, L., Sorensen, C., \& Razavieh, A. (2010). Introduction to research in education. Wadsworth: Cengage Learning.

Benson, P. (1997). The philosophy and politics of learner autonomy. In P. Benson, \& P. Voller (Eds.), Autonomy and independence in language learning (pp. 18-34). London: Longman.

Benson, P., \& Cooker, L. (Eds.). (2013). The applied linguistic individual: Sociocultural approaches to autonomy, agency and identity. London, UK: Equinox.

Canale, M. (1983). From communicative competence to communicative language pedagogy. In J. C. Richards, \& R. Schmidt (Eds.). Language and communication. London: Longman Group.

Ceylan, N. O. (2015). Fostering learner autonomy. Procedia-Social and Behavioral Sciences, 199, 85-93.

Ceylan, N. O. (2017). Does Training Learners on Language Learning Strategies Have Any Effect on Language Achievement? European Journal of Sustainable Development, 6(4), 405-415.

Chen, H.-I., \& Pan, H.-H. (2015). Learner Autonomy and the Use of Language Learning Strategies in a Taiwanese Junior High School. Journal of Studies in Education, 5(1), 52-64.

Chen, N.-S., \& Hsieh, S.-W. (2008). Effects of short-term memory and content representation type on mobile language learning. Language Learning and Technology 12(3), 93113.

Chinnery, G. M. (2006). Emerging Technologies: Going to the MALL (Mobile Assisted Language Learning). Language Learning \& Technology, 10(1), 9-16.

Clarke, B. \& Svanaes, S. (2014). An Updated Literature Review on the Use of Tablets in Education. London: Techknowledge for Schools.

Clouston, M. (1997). Language learning strategies: An overview for L2 teachers. The Internet TESL Journal, 3(12), 69-80.

Cohen, J. (1988). Statistical power analysis for the behavioral sciences (2nd ed.). Hilsdale, NJ: Lawrence Earlbaum Associates.

Cotterall, S. (1995). Readiness for Autonomy: Investigating Learner Beliefs. System, 23(2), 195-205.
Dickinson, L. (1995). Autonomy and Motivation a Literature Review. System, 23(2), 165-174.

Dornyei, Z. (2007). Research methods in applied linguistics: Quantitative, qualitative, and mixed methodologies. New York: Oxford University Press.

Etxebarria, A., Garay, U. \& Romero, A. (2012). Implementation of social Strategies in Language Learning by Means of Moodle. Journal of Language Teaching and Research, 3 (2), 273-282.

Farooq, M. U. (2013). Effects of learner autonomy on teaching practices and outcomes in an ELT classroom. European Journal of Scientific Research, 94, 316-330.

Godwin-Jones, R. (2011). Emerging Technologies: Mobile Apps for Language Learning. Language Learning \& Technology, 15(2), 2-11.

Green, J. M., \& Oxford, R. (1995). A closer look at learning strategies, L2 proficiency, and gender. TESOL Quarterly, 29, 261-297.

Habte-Gabr, E. (2006). The importance of socio-affective strategies in using EFL for teaching mainstream subjects. The Journal of Humanizing Language Teaching, 8(5), 1-5.

Hazaea, A. N., \& Alzubi, A. A. (2016). The Effectiveness of using mobile on EFL learners' reading practices in Najran University. English Language Teaching, 9(5), 8-21.

Hismanoglu, M. (2000). Language learning strategies in foreign language learning and teaching. The Internet TESL Journal, $6(8), 12-12$.

Holec, H. (1981). Foreign Language Learning. Oxford: Pergamon Press.

Jacobs, G. M. (2006). Issues in implementing cooperative learning. In S. G. McCafferty, G. M. Jacobs, \& C. D. Iddings (Eds.), Cooperative learning and second language teaching (pp. 30- 46). New York, NY: Cambridge University Press.

Jeffries, L., \& Mikulecky, B. (2014). Reading Power 1 (3rd ed.). UK: Pearson Longman.

Kasper, M., Uibu, K., \& Mikk, J. (2018). Language Teaching Strategies' Impact on Third-Grade Students' Reading Outcomes and Reading Interest. International Electronic Journal of Elementary Education, 10(5), 601-610

Kukulska-Hulme, A., \& Shield, L. (2008). An overview of mobile assisted language learning: From content delivery to supported collaboration and interaction. ReCALL, 20(3), 271-289.

Kukulska-Hulme, A., \& Traxler, J. (2005). Mobile learning: A handbook for educators and trainers. London: Routledge.

Little, D. (1991). Autonomy: Definitions, Issues and Problems. Dublin: Authentik.

Mistar, J. (2015). Maximing Learning Strategies to Pomote Learner Autonomy. TEFLIN Journal, 12(1), 88-100.

Murase, F. (2007). Operationalising the Construct of Learner Autonomy: A Preliminary Study for Developing a New Measure of Language Learner Autonomy. Paper presented at the proceedings of Independent Learning Association 2007 Japan Conference: Exploring Theory, Enhancing Practice, 
Murase, F. (2007). Operationalising the Construct of Learner Autonomy: A Preliminary Study for Developing a New Measure of Language Learner Autonomy. Paper presented at the proceedings of Independent Learning Association $2007 \mathrm{Ja}$ pan Conference: Exploring Theory, Enhancing Practice, held in Kanda University of International Studies, Chiba, Japan.

Nezami, S. R. A. (2012). A critical Study of Comprehension Strategies and General Problems in Reading Skill Faced by Arab EFL Learners with Special Reference to Najran University in Saudi Arabia. International Journal Social Science and Education, 2(3), 306-316.

Nguyen, L. T. C., \& Gu, Y. (2013). Strategy-based instruction: A learner-focused approach to developing learner autonomy. Language Teaching Research, 17(1), 9-30.

Nino, A. (2015). Language Learners Perceptions and Experiences on the Use of Mobile Applications for Independent Language Learning in Higher Education. IAAFOR Journal of Education, 73-84.

Norton, B. (2000). Identity and language learning: Gender, ethnicity and educational change. New York: Longman.

Norton, B. (2001). Non-participation, imagined communities and the language classroom. In M.P. Breen (ed.), Learner Contributions to Language Learning: New Directions in Research. Harlow: Longman.

O'Malley, J. M., \& Chamot, A. U. (1990). Learning Strategies in Second Language Acquisition. Cambridge: Cambridge university press.

Oxford, R. (2003). Toward a more systematic model of L2 learner autonomy. In D. Palfreyman \& R. Smith (Eds.), Learner autonomy across cultures: language education perspectives (pp. 75-91). New York: Palgrave Macmillan.

Oxford, R. (2011). Teaching and researching language learning strategies. Harlow, United Kingdom: Pearson/Longman.

Oxford, R. L. (1990). Language learning strategies: what every teacher should know. Boston: Heinle and Heinle.

Palfreyman, D. M. (2012). Chapter Eight Bringing the World into the Institution: Mobile Instructional Learning for Staff and Students. Left to my own Devices: Learner Autonomy and Mobile-Assisted Language Learning: Learner Autonomy and Mobile-assisted Language Learning, 6, 163.

Pennycook, A. (1997). Cultural Alternatives and Autonomy. In P. Benson \& P. Voller (Eds.), Autonomy and Independence in Language Learning (pp. 35-53). London: Longman.

Persson, V., \& Nouri, J. (2018). A Systematic Review of Second Language Learning with Mobile Technologies. International Journal of Emerging Technologies in Learning (iJET), 13(02), 188-210.

Rahimi, M., \& Miri, S. S. (2014). The impact of mobile dictionary use on language learning. Procedia-Social and Behavioral Sciences, 98, 1469-1474.

Rahman, M. M., \& Alhaisoni, E. (2013). Teaching English in Saudi Arabia: prospects and challenges. Academic Research International, 4(1), 112-118.

Reinders H. (2010). Twenty Ideas for Using Mobile Phones in the Language Classroom. English Language Teaching Forum, 46(3), 20-25, 33.
Reinders, H., \& Hubbard, P. (2013). CALL and learner autonomy: Affordances and constraints. In M. Thomas, H. Reinders, \& M. Warschauer (Eds.), Contemporary computer assisted language learning (pp. 359-375). London, UK: Continuum Books.

Salehi, H., Ebrahimi, M., Sattar, S., \& Shojaee, M. (2015). Relationship between EFL Learners' Autonomy and Speaking Strategies They Use in Conversation Classes. Advances in Language and Literary Studies, 6(2), 37-43.

Seddigh, F., \& Shokrpur, N. (2012). Vocabulary learning strategies of medical students at Shiraz University of Medical Sciences. English Language Teaching, 5(2), 160-173.

Slavin, R. E. (1988). Synthesis of research on grouping in elementary and secondary schools. Educational Leadership, 46(1), 67-77.

Su, M.-h. M., \& Duo, P.-c. (2010). EFL learners' language learning strategy use as a predictor for self-directed learning readiness. The Journal of AsiaTEFL, 7(2), 153-176.

Tamer, O. (2013). Students' Readiness for Autonomous Learning of English as a Foreign Language (master's thesis). University of Sunderland, England.

Thornton, P., \& Houser, C. (2003). Using mobile web and video phones in English language teaching: Projects with Japanese college students. In B. Morrison, C. Green \& G. Motteram (Eds.), Directions in CALL: Experience, experiments \& evaluation (pp. 207-224). Hong Kong: English Language Center, Hong Kong Polytechnic University.

Timirbaeva, G. R. (2013). Language learning strategies and their impact on learner autonomy. Paper presented at the International Conference on Interactive Collaborative Learning (ICL), 2013, 621-622.

Varisoglu, M. C. (2016). The importance of strategies of social language learning and cooperative learning in the process of teaching Turkish as a foreign language. Educational Research and Reviews, 11(10), 981-986.

Vygotsky, L. (1978). Mind in society: The development of higher psychological processes. Cambridge: Harvard University Press.

White, H., \& Sabarwal, S. (2014). Quasi-experimental design and methods (Methodological Briefs: Impact Evaluation, 8. Retrieved from https://www.unicefirc.org/publications/ pdf/brief_8_quasi-experimentaldesign_eng.pdf

Wong, L.-H., Chin, C.-K., Tan, C.-L., \& Liu, M. (2010). Students' personal and social meaning making in a Chinese idiom mobile learning environment. Educational Technology \& Society, 13(4), 15-26. 